\title{
QUESTÕES CONTROVERSAS COM RELAÇÃO À LEI DO FEMINICÍDIO (LEI N. 13.104/2015)*
}

\author{
CONTROVERSIAL ISSUES REGARDING FEMICIDE LAW (LAW NO. 13,104/2015)
}

\author{
Luciano Anderson de Souza** \\ Paula Pécora de Barros ${ }^{* * *}$
}

\begin{abstract}
Resumo:
O artigo analisa a chamada Lei do Feminicídio, isto é, Lei n. 13.104/2015, que alterou o delito de homicídio no Código Penal pátrio, para fins de inclusão de uma novel qualificadora, consistente no homicídio praticado contra a mulher, por razões da condição de sexo feminino. Procede-se a um estudo de viés crítico eminentemente político-criminal e dogmático penal, com breves referências criminológicas. São destacados os paradoxos da busca pela utilização legítima do ramo jurídico-criminal para fins de emancipação de um grupo vulnerável, marginalizado em sociedade machista e patriarcal.
\end{abstract}

Palavras-chave: Feminicídio. Lei n. 13.104/2015. Violência de gênero. Homicídio qualificado. Lei Maria da Penha. Direito Penal simbólico.

\begin{abstract}
:
The paper analyzes the so-called Femicide Act, i.e. Law No. 13,104/2015, which amended the crime of murder in the Brazilian Criminal Code, for the purpose of inclusion of a new qualifying, consisting of murder committed against women for reasons of female gender condition. It proceeds to a study of eminently politicalcriminal bias and critical criminal dogmatic, with brief criminological references. The paradoxes of the search for the legitimate use of the legal and criminal branch for emancipation purposes of a vulnerable group, marginalized in a sexist and patriarchal society are highlighted.
\end{abstract}

Keywords: Femicide. Law No. 13,104/2015. Gender violence. Degree murder. Maria da Penha Law. Symbolic Criminal Law.

\footnotetext{
O presente texto foi produzido com exclusividade para a Revista da Faculdade de Direito da Universidade de São Paulo para fins de divulgar reflexões parciais produzidas no âmbito do Projeto intitulado "Desafios político-criminais e dogmáticos quanto à violência de gênero e sexualidade na legislação penal brasileira", financiado pelo Programa Unificado de Bolsas de Estudos da Reitoria da Universidade de São Paulo (USP) nos anos 2015/2016, tendo o primeiro autor como docente coordenador da pesquisa e a segunda autora como bolsista responsável pelo tema "feminicídio".

** Professor Doutor de Direito Penal do Departamento de Direito Penal, Medicina Forense e Criminologia da Faculdade de Direito da Universidade de São Paulo.

*** Graduanda do curso de Direito da Faculdade de Direito da Universidade de São Paulo. Bolsista do Programa Unificado de Bolsas de Estudos da Reitoria da Universidade de São Paulo, nos anos 2015/2016, quanto ao Projeto de pesquisa "Desafios político-criminais e dogmáticos quanto à violência de gênero e sexualidade na legislação penal brasileira", responsável pelo tema "feminicídio".
} 


\section{Considerações iniciais}

Em 9 de março de 2015, seguindo tendência de outros países da América Latina, o Brasil insculpiu a previsão criminal do chamado feminicídio, por meio da Lei n. 13.104/2015. Desse modo, no ordenamento pátrio, o feminicídio foi elencado como qualificadora do homicídio, consubstanciando, de acordo com a redação legislativa dada, em modalidade deste último delito, quando praticado contra a mulher por razões da condição de sexo feminino. No contexto latino-americano, a penalização do feminicídio é recente, sendo que a maioria dos países da região criou formas diferenciadas de se coibir essa modalidade de delinquência de gênero, seja propriamente tipificando o feminicídio, ou femicídio, seja reformando o Código Penal ou, ainda, estabelecendo agravantes respectivas. ${ }^{1}$

No caso brasileiro, a tipificação do feminicídio é considerada uma continuação da política legislativa iniciada com a chamada Lei Maria da Penha no enfrentamento à violência contra a mulher. Apesar dos reconhecidos avanços tidos pela Lei n. 11.340/2006, principalmente em sua parte extrapenal, verifica-se uma carência em sua tutela criminal, pois disciplina de forma diferenciada, basicamente, apenas lesões corporais em razão da violência doméstica, não abarcando a morte decorrente desse tipo de violência. ${ }^{2} \mathrm{O}$ país possui a taxa de 4,8 homicídios de mulheres por 100 mil habitantes e se classifica como o $5^{\circ}$ país com mais mortes de mulheres, somente atrás de El Salvador, Colômbia, Guatemala e Federação Russa. ${ }^{3}$

É visando atender às demandas de tutela para suprir esta carência que a Comissão Parlamentar Mista de Inquérito (CPMI) de Violência contra a Mulher apresentou relatório final com proposta de lei cuja tramitação começou no Senado e seria sancionada em março de 2015, após anúncio realizado no dia internacional da mulher, transformandose na citada Lei n. 13.104/2015, que alterou a redação do art. 121 do Código Penal. Assim, o artigo passou a definir em seu $\S 2^{\circ}$, inciso VI, o feminicídio, isto é, o homicídio praticado contra a mulher por razões da condição de sexo feminino, como crime qualificado. Foi ainda insculpido regrame de interpretação autêntica por meio do novel $\S 2^{\circ}$-A, que fixa: "considera-se que há razões de condição de sexo feminino quando o crime envolve: Iviolência doméstica e familiar; II - menosprezo ou discriminação à condição de mulher".

1 Atualmente, incluindo-se o Brasil, são dezesseis os países latino-americanos que preveem o feminicídio, ou femicídio, por legislação extravagante ou por alteração produzida no interior do Código Penal. As penas, no geral, são superiores à estabelecida na realidade pátria.

2 SOUZA, Luciano Anderson de; FERREIRA, Regina Cirino Alves, Feminicídio: primeiras observações. Boletim IBCCRIM, São Paulo, n. 269, p. 3-4, abril 2015. p. 3-4.

3 WAISELFISZ, Julio Jacobo. Mapa da violência 2015. Homicídio de mulheres no Brasil. Brasília: FLACSO, 2015. Disponível em: <http://www.mapadaviolencia.org.br/pdf2015/MapaViolencia_2015_mulheres.pdf>. p. 27. 
Desse modo, o feminicídio passa a ser expressamente tratado como espécie de homicídio qualificado e, por conseguinte, crime hediondo.

O legislador houve por bem, ademais, estabelecer causas de aumento de pena aplicáveis exclusivamente à nova qualificadora. Neste sentido, a pena do feminicídio é aumentada de um terço até a metade, segundo o $\S 7^{\circ}$ de mesmo artigo, se o crime for praticado: "I -durante a gestação ou nos 3 (três) meses posteriores ao parto; II - contra pessoa menor de 14 (catorze) anos, maior de 60 (sessenta) anos ou com deficiência; IIIna presença de descendente ou de ascendente da vítima".

Político-criminalmente, a busca pelo sistema penal por parcela do movimento feminista não é algo inédito para o caso da violência de gênero. No contexto de edição da Lei Maria da Penha, a pressão por maior atuação estatal levou também à alteração de dispositivos penais, o que tem suscitado diversas críticas desde sua aprovação, assim como agora ocorre com a Lei do Feminicídio. Dessa maneira, a aprovação do diploma em foco suscita amplos debates e questionamentos, alguns dos quais serão mencionados infra. Para além da reflexão quanto à legitimidade de tutela penal nesta seara, ademais, há críticas dogmáticas erigidas a partir da conformação concreta estabelecida pela legislação em comento, as quais não podem ser descuradas.

Neste influxo, para fins de se fomentar o importante debate, ainda que inicial, em torno da legislação posta, a análise formulada no presente texto perpassa pelos seguintes tópicos: (i) a diferenciação semântica entre os conceitos de feminicídio e de femicídio; (ii) a utilização do termo "razões da condição de sexo feminino" e a possível aplicação da qualificadora para casos de vítimas transexuais; (iii) a forma que se dá a aplicação da lei em casos de violência doméstica e familiar; (iv) os problemas dogmáticos presentes nas causas de aumento previstas; (v) a estigmatização da mulher feita pelo sistema penal, ao rotulá-la como vítima e vulnerável, e (vi) a utilização do Direito Penal com viés simbólico na hipótese.

\section{Diferenciação semântica entre feminicídio e femicídio}

Os conceitos de feminicídio e de femicídio ${ }^{4}$ são atualmente utilizados com frequência no continente latino-americano, e o seu uso se relaciona à vontade de fazer emergir um contexto de enunciação da violência contra as mulheres, promovendo novas

Sobre o tema, e.g., cf. LAPALUS, Marylène. Feminicidio/femicidio: les enjeux théoriques et politiques d'un discours définitoire de la violence contre les femmes. Enfances, Familles, Générations, [S.1.], n. 22, 2015, p. 85-113. Disponível em: <http://www.efg.inrs.ca/index.php/EFG/article/view/432/255>; TOLEDO VÁSQUEZ, Patsilí. Femicidio/feminicidio. Buenos Aires: Didot, 2014, passim; SOUZA, Regina Cirino Alves Ferreira de. Ódio e direito penal. Dissertação (Mestrado) - Faculdade de Direito, Universidade de São Paulo, São Paulo, 2016. p. 136-142. 
categorias e definições que levem à questão fundamental da visibilização das violências de gênero e à luta pela sua erradicação.

Apesar desses conceitos terem, em um primeiro momento, uma definição comum e geral, como "os assassinatos cometidos por homens contra mulheres em razão de serem mulheres", 5 eles não são semanticamente equivalentes, e foram utilizados e analisados de maneiras distintas nas últimas décadas. Faz-se, portanto, necessária uma análise linguística sob uma perspectiva sociológica.

Diana Russel, Jill Radford, Jane Caputi e Liz Kelly, ${ }^{6}$ foram as primeiras a trabalharem na definição de femicide, colocando em uso diversos conceitos da reflexão feminista sobre a violência masculina contra as mulheres: o conceito de crime sexual, o reconhecimento da violência no espaço público e privado, a ideia de um continuum de violência e até mesmo o papel exercido por certas instituições nessa violência.

Quanto à relação com a violência sexual, se coloca em evidência o caráter político do crime sexual, não tendo o significado presente no senso comum de ter a intenção de uma relação sexual com a violada, mas em um sentido de desejo de poder e controle dos homens. Sendo uma forma de controle das mulheres por parte dos homens, ${ }^{7}$ o femicídio deve ser denunciado tanto nas esferas privada e pública. Em uma relação de espaço doméstico desvela-se maior risco de violência vinda de marido, companheiro, pai ou irmão. Todavia, a relação de dominação se reproduz no espaço público, onde a mulher deve obter a aprovação masculina.

Traduzindo o conceito de femicide para os respectivos contextos nacionais, as definições de femicídio e de feminicídio foram formuladas, respectivamente, por Ana Carcedo e Montserrat Sagot, na Costa Rica, e Marcela Lagarde e Julia Monárrez, no México, no final dos anos 1990, determinando duas grandes tendências no continente latino-americano.

Ambos conceitos, assim como o original femicide, buscam efetuar uma ruptura com o senso comum, explicitando uma realidade até então invisível e demonstrando a importância e pertinência de analisar os crimes contra as mulheres pelo ângulo do gênero, conceito o qual apreende a origem social das discriminações e as relações assimétricas entre mulheres e homens na sociedade. ${ }^{8}$ Com a utilização de uma nova categoria para designar a especificidade da maioria dos homicídios cometidos contra mulheres, questiona-se a utilização tradicional da língua, ${ }^{9}$ pois os conceitos antes

RADFORD, Jill; RUSSELL, Diana E. H. Femicide: the politics of woman killing. New York: Twayne Publishers, Sept. 1992. p. 3-4.

6 RADFORD, Jill; RUSSEL, Diana E. H. Femicide... cit., p. 3-5.

7 RADFORD, Jill; RUSSEL, Diana E. H. Femicide... cit., p. 6.

8 LAPALUS, Marylène. Feminicidio/femicidio..., cit., p. 93.

9 Neste sentido, e.g., cf. CHUECA SANCHO, Ángel. Vulnerabilidad de las mujeres, principio de igualdad y 
existentes (homicídio ou morte de mulheres) não mais seriam suficientes para determinar a experiência de violência vivida.

O termo alcunhado como femicídio contribui para ressaltar o caráter social e generalizado da violência baseada na iniquidade de gênero, afastando enfoques individualizantes, naturalizados ou patologizados, que tendem a culpar as vítimas, a tratar o assunto como problemas passionais ou privados e a ocultar a sua verdadeira dimensão, bem como as experiências das mulheres e a responsabilidade dos homens.

Um setor do feminismo latino-americano considerou insuficiente a palavra femicídio para captar o caráter massivo que por vezes ocorrem nos casos de assassinatos de mulheres que só poderiam ser explicados pela impunidade generalizada que permeia essas condutas. ${ }^{10}$ Daí se viu a necessidade de construir um conceito capaz de refletir não somente a responsabilidade individual dos autores, como também a sua dimensão institucional, a corresponsabilidade do Estado pela sua inoperância no momento de prevenir e castigar esse tipo de crime, inoperância cujas raízes se encontram em fatores de gênero. Essas omissões estatais levam a uma sensação de impunidade generalizada que favorece a proliferação dos atentados contra a vida das mulheres.

Assim, foi acunhado o conceito feminicídio, mais vinculado à ideia de genocídio do que de assassinatos individuais, por Marcela Lagarde, para denunciar o conjunto de delitos que lesam a humanidade, apontando a dimensão de crimes do Estado. Neste sentido, o feminicídio é visto a partir da perspectiva de ponto de convergência de contínuas violências ${ }^{11}$ que mulheres sofrem no dia a dia, que têm raízes na cultura sexista e misógina ainda existente. Intimidações, ameaças, abuso verbal, físico, estupro, tortura, mutilações genitais, etc. ocorrem constantemente na vida de milhões de mulheres, aliadas a outras formas de violência presentes na realidade, de utilização das mulheres na pornografia, na exploração sexual, a esterilização ou a maternidade forçadas ou a imposição de cirurgias plásticas desnecessárias, assim como violências institucionais. ${ }^{12}$

Lagarde, ao incluir o fator impunidade, tratou do feminicídio como uma violência praticada por homens em posição de supremacia social, sexual, jurídica, econômica, política, ideológica e de todo tipo, sobre mulheres em condições de desigualdade, de subordinação, de exploração ou de opressão. Seu posicionamento,

no discriminación y derechos humanos. In: ALCOCEBA GALLEGO, Amparo; QUISPE REMÓN, Florabel (Coord.). Feminicidio: el fin de la impunidad. Valencia: Tirant lo Blanch, 2013. p. 37-53. p. 37.

10 COPELLO, Patricia Laurenzo. ¿Hace falta un delito de feminicidio? Revista de Derecho Penal, Montevidéu, v. 20, p. 243-256, 2012. p. 243-256.

11 RADFORD, Jill; RUSSEL, Diana E. H. Femicide... cit., p. 15.

12 Nas quais se incluem, por exemplo, econômicas, sociais, culturais e educacionais. Neste sentido, v.g., cf. CHUECA SANCHO, Ángel. Vulnerabilidad de... cit., p. 38. 
todavia, ao inclinar-se a uma responsabilização institucional, afastou a adesão inicial de Russel. ${ }^{13}$

Apesar de distinções conceituais pontuais, as duas expressões em foco são tomadas como sinônimos pelas legislações latino-americanas e em parte da literatura feminista, o que não parece desejável diante da necessidade de uma tutela harmonizada a contextos sociais similares. Na construção categorial delitiva de feminicídio no Brasil, previu-se sua aplicação para casos de homicídios de mulheres pelas condições de serem mulheres, não adquirindo, portanto, dimensão política de omissão do Estado, ou de seus agentes. ${ }^{14}$ Se adquirisse em alguma medida, entretanto, ao que tudo indica, seria contraditório, visto que tal lei parece buscar exatamente suprir demandas por maior atuação estatal, vez que não se viu acompanhada de políticas públicas com foco no tema.

De qualquer forma, diante da previsão do crime de genocídio na legislação brasileira, ${ }^{15}$ com a confirmação que lhe é dada, não tendo sofrido qualquer alteração atinente a gênero, não se sinaliza como dogmaticamente mais adequada a rotulação de feminicídio. Em outras palavras, verifica-se que a utilização de femicídio, em que pese as críticas formuladas por parcela do movimento feminista, ostenta-se como mais adequada em consonância com o legislado em nosso país. Mas os problemas da Lei do Feminicídio trespassam - e muito - a questão da nomenclatura, conforme se aponta abaixo.

\section{Razões do sexo feminino e aplicação da lei para vítimas transexuais}

Dentre diversas falhas verificadas na Lei do Feminicídio, encontra-se a supressão do termo gênero no seu texto final, com sua substituição por sexo feminino, ${ }^{16}$ fato que ocorreu conscientemente por parte dos parlamentares, em meio a manobras para diminuir o alcance da lei e impedir sua aplicação a vítimas mulheres transexuais, ${ }^{17}$ alcançadas que seriam pela identidade de gênero. $O$ conceito de gênero se diferencia

13 Neste sentido, cf. SOUZA, Regina Cirino Alves Ferreira de. Ódio e... cit., p. 139-140.

14 Com relação a eventual responsabilização do ente estatal, de acordo com a configuração constitucional penal brasileira, tal somente poderia incidir em termos extrapenais.

15 Lei n. 2.889/1956.

16 A Emenda de Redação n. 1 do Projeto de Lei n. 8.305/2014, que originou a Lei n. 13.104/2015, apresenta a rejeição dos deputados ao conceito de gênero e a sua substituição por "condição de sexo feminino".

17 Cf. Castilho: "Na Câmara dos Deputados a cláusula definidora do feminicídio: 'razões de gênero' foi substituída por "razões de condição de sexo feminino". A substituição foi qualificada como emenda de redação, para justificar a não devolução do projeto à Câmara. Mas bem sabemos que não se trata de mera emenda de redação, pois visou restringir a aplicabilidade do feminicídio a transexuais mulheres. Ademais, a palavra gênero é perigosa, pois subverte a ordem, dita da natureza, do binarismo sexual de machos e fêmeas". CASTILHO, Ela Wiecko Volkmer de. Sobre o feminicídio. Boletim IBCCRIM, São Paulo, v. 270, p. 4-5, maio 2015. p. 4. 
daquele de sexo para as ciências sociais, ${ }^{18}$ atingindo com maior propriedade o escopo da disciplina.

É sempre grande a repercussão ao redor do tema "sexualidade e gênero", principalmente em uma sociedade que parece se esforçar em fingir que não há outras formas de identidades, relacionamentos e famílias. A pessoa transexual é aquela que se identifica com o sexo oposto ao seu biológico, geralmente passando a se vestir e a se comportar da mesma forma que o sexo desejado, bem como podendo adotar procedimentos clínicos e químicos de mudança corporal, para realização pessoal. ${ }^{19}$

Concretamente, a diferença decorrente da não identificação do sujeito em seu sexo de nascimento é usada como mecanismo para não efetivar garantias. Assim, aqueles que não se encaixam no sistema binário socialmente construído acabam tendo violados e não efetivados diversos direitos. Dessa forma, a chamada população trans (travestis, transexuais e transgêneros) sofre extrema vulnerabilidade, sendo muito raras as políticas públicas realizadas para proteção desse grupo marginalizado. A Lei do Feminicídio, lamentavelmente, apenas corrobora tal percepção.

É inegável a necessidade da Lei do Feminicídio ser aplicada para as mulheres transexuais, vez que foi criada para reduzir o alto índice de violência contra a mulher, do qual também sofrem as "mulheres cis" (mulheres que têm identidade de gênero e sexo biológico feminino), assim como as "mulheres trans" (mulheres com sexo biológico masculino e identidade de gênero feminina), as quais podem igualmente figurar como sujeitos passivos, ao serem vitimadas pela reprodução do modelo de violência machista. Contudo, a Lei do Feminicídio explicita o caso em que pode ser aplicada: quando a vítima é do sexo feminino. Em face do histórico legislativo, que suprimiu a palavra "gênero", assim como diante do fato de que norma restritiva se interpreta restritivamente, a escorreita exegese sinaliza pelo entendimento de que pertence ao sexo feminino tão somente a pessoa identificada como tal pelos registros oficiais, ${ }^{20}$ o que é de todo indesejado. ${ }^{21}$

A gravidade dos meios utilizados na repressão do delito impõe a necessidade de princípios capazes de limitá-lo. ${ }^{22}$ Dentre eles está o princípio da legalidade, um

18 Neste artigo é feita a distinção de gênero e sexo considerando o primeiro como uma construção social e o segundo referente a características biológicas e anatômicas. Esta é a distinção mais comum na lei e no movimento feminista, e por isso é a aplicada apesar de haver debate e dissenso sobre essa questão dentro do movimento LGBTT. Sobre a construção social dos corpos, cf., e.g., BOURDIEU, Pierre. A dominação masculina. Rio de Janeiro: Bertrand Brasil, 2010. p. 15 e ss.

19 COUTO, Edvaldo Souza. Transexualidade. O corpo em mutação. Salvador: Grupo Gay da Bahia, 1999. p. 26.

20 Em sentido similar, v.g., cf. BITENCOURT, Cezar Roberto. Tratado de direito penal. São Paulo: Saraiva, 2016, v. 2. p. 101.

21 Demonstrando as dificuldades advindas da construção legal efetuada, cf. SOUZA, Regina Cirino Alves Ferreira de. Ódio e... cit., p. 142 e ss.

22 BITENCOURT, Cezar Roberto. Tratado de direito penal. São Paulo: Saraiva, 2014, v. 1. p. 50-53. 
imperativo que não admite desvios na aplicação da norma penal. A lei deve, portanto, definir com precisão a conduta proibida, e para isso as expressões não podem ser imprecisas ou ambíguas. A partir desse corolário, aduz-se o princípio da taxatividade, no qual o legislador deve determinar explicitamente as condutas subsumidas no tipo penal, assim como o princípio da proibição da analogia in malam partem. Dessa forma, seria contrário ao ordenamento jurídico uma interpretação extensiva no âmbito do Direito Penal que abarcasse os casos de assassinato de mulheres transexuais, vez que isso se daria em prejuízo do réu. Faz-se, portanto, imprescindível a alteração da letra da lei para que estas mulheres também possam ser inequivocamente abarcadas.

\section{Aplicação em caso de violência doméstica e familiar}

Visando explicitar as situações que seriam consideradas como crime praticado contra a mulher por razões da condição do sexo feminino, os referidos incisos I e II do novel $\S 2^{\circ}$-A, respectivamente, definem que estas serão aferidas nos casos que envolvam violência doméstica e familiar ou, ainda, menosprezo ou discriminação à condição de mulher.

Quanto ao primeiro inciso, o legislador buscou maior alargamento na aplicação da lei ao colocar a situação de crime em meio doméstico e familiar, demonstrando seu caráter de continuidade da Lei Maria da Penha. Isto se deve a uma razão prática: o homicídio de mulheres na sociedade brasileira, em geral, possui contextualização distinta da de homens, ocorrendo em grande parte no ambiente doméstico. ${ }^{23}$ Assim, procurando afastar maiores dificuldades na interpretação da morte decorrente de um contexto doméstico opressivo como um assassinato misógino, a lei a fixou expressamente como feminicídio.

Com isso, buscou-se rechaçar a possibilidade de qualquer dúvida do aplicador do direito sobre quando e como determinar se em uma relação de natureza doméstica e familiar poderá incidir a qualificadora. ${ }^{24}$ Isso porque se considera violência doméstica e familiar ${ }^{25}$ de acordo com o conceito extraído da Lei Maria da Penha, em

${ }_{23}$ "Quase a metade dos homicídios masculinos acontece na rua, com pouco peso do domicílio. Já nos femininos, essa proporção é bem menor: mesmo considerando que 31,2\% acontecem na rua, o domicílio da vítima é, também, um local relevante (27,1\%), indicando a alta domesticidade dos homicídios de mulheres". WAISELFISZ, Julio Jacobo. Mapa da... cit., p. 39.

24 ZANELlA, Everton; FRIGGI, Márcio; ESCUDEIRO, Marcio; AMARAL, Virgílio. Feminicídio: considerações iniciais. Centro de Apoio Operacional Criminal do Ministério Público do Estado de São Paulo. São Paulo, 2 de junho de 2015. Disponível em: <http://www.mpsp.mp.br/portal/page/portal/cao_ criminal/Artigos>.p. 4 e ss.

25 Bitencourt considera inadequada a utilização da conjunção aditiva " $e$ " no inciso em foco, eis que poderia dar margem a discussões judiciais, já que nem toda violência doméstica é familiar e vice-versa. Cf. BITENCOURT, Cezar Roberto. Tratado de... cit., v. 2, p. 97. 
seu art. 50 ${ }^{26}$ Em vista disso, a qualificadora pode ser considerada de natureza objetiva, constituindo "quadro fático-objetivo não atrelado, aprioristicamente, aos motivos determinantes da execução do ilícito". ${ }^{27}$

Seguindo tal interpretação, no entanto, considera-se possível que a qualificadora seja aplicada em casos em que não houver propriamente discriminação por condição de ser mulher, demonstrando possível equívoco de tal dado objetivo estar inserido em disposição que trata de circunstâncias de natureza subjetiva, ou seja, pela motivação do crime em razão da condição de sexo feminino. A norma presente no inciso II, por outro lado, dependerá de interpretação do aplicador, que deverá definir a extensão da expressão menosprezo ou discriminação à condição de mulher. Esse inciso abarca cenário maior do que violência doméstica ou familiar, e será aplicado em qualquer situação de fato que não ocorra no âmbito doméstico, familiar ou de relação íntima entre o agente e a vítima, devendo necessariamente nesse inciso haver menosprezo ou discriminação contra a mulher.

Para auxiliar a compreensão do aplicador, poderá ser considerado como um caso de discriminação contra a mulher quando presente "qualquer ato ou conduta baseada no gênero, que cause morte, dano ou sofrimento físico, sexual ou psicológico à mulher, tanto na esfera pública como na esfera privada" ${ }^{28}$ Assim, a verificação, neste inciso, dependerá de alguma avaliação subjetiva da motivação, em acordo com a qualificadora.

É importante, contudo, a crítica de que tal subjetividade poderá gerar distorções na sua aplicação, sendo possível que chegue até mesmo a ser aplicado de forma banalizada apenas porque o homicídio ostente como vítima a mulher. Para evitar tal aplicação, demanda-se uma valoração das provas, assim como uma melhor delimitação por parte da doutrina e da jurisprudência com relação aos casos aplicáveis neste inciso.

${ }_{26}$ "Art. 5". Para os efeitos desta Lei, configura violência doméstica e familiar contra a mulher qualquer ação ou omissão baseada no gênero que lhe cause morte, lesão, sofrimento físico, sexual ou psicológico e dano moral ou patrimonial: I - no âmbito da unidade doméstica, compreendida como o espaço de convívio permanente de pessoas, com ou sem vínculo familiar, inclusive as esporadicamente agregadas; II - no âmbito da família, compreendida como a comunidade formada por indivíduos que são ou se consideram aparentados, unidos por laços naturais, por afinidade ou por vontade expressa; III - em qualquer relação intima de afeto, na qual o agressor conviva ou tenha convivido com a ofendida, independentemente de coabitação. Parágrafo único. As relações pessoais enunciadas neste artigo independem de orientação sexual'.

27 ZANELla, Everton; FRIGGI, Márcio; ESCUDEIRO, Marcio; AMARAL, Virgílio. Feminicídio: considerações... cit., p. 5.

28 Entendimento retirado a partir da Convenção Interamericana para Prevenir, Punir e Erradicar a Violência contra a Mulher (Convenção de Belém do Pará), de 9 de junho de 1994. 
5. Problemas dogmáticos nas causas de aumento

A Lei do Feminicídio procurou introduzir uma especial proteção às mulheres em situação de vulnerabilidade, aumentando a pena, de 1/3 até a metade, quando o feminicídio for praticado contra mulheres gestantes ou nos três meses posteriores ao parto, contra menor de 14 anos, maior de 60 anos ou com deficiência, ou nos crimes presenciados por descendente ou ascendente da vítima. Também quanto a tudo isso, inúmeras dificuldades são postas.

A fundamental crítica incisiva com relação às causas de aumento em análise diz respeito à ofensa ao princípio da igualdade. Se são hipóteses que revelam maior censurabilidade da ação do agente, em razão da maior dificuldade de autodefesa da vítima, ou trauma produzido em seus parentes que presenciaram o crime, por que isso haveria de cingir-se exclusivamente ao feminicídio e não a todas as hipóteses de homicídio? Neste sentido, afigura-se como simplesmente demagógica a limitação a tais casos.

A primeira hipótese prevista refere-se ao feminicídio praticado contra mulheres gestantes ou nos três meses posteriores ao parto. Nunca é demais lembrar que, tanto nesta como em todas as demais hipóteses, o agente deverá conhecer a circunstância para fins de reconhecimento da majorante, vez que o dolo deve incidir sobre todas as elementares. As divergências quanto aos elementos normativos atrelados ao início da gestação ou do parto se farão presentes no caso.

A segunda causa de aumento de pena, tocante à pessoa menor de 14 ou maior de 60 anos, já se encontrava prevista no $\S 4^{\circ}$ do art. 121 , que estabelece um aumento de 1/3 para esses casos em qualquer situação de homicídio. Ao que tudo indica, o que houve foi uma profunda desatenção quanto à sistemática do delito que se procurou alterar. De qualquer forma, resta uma peculiaridade com relação ao feminicídio, consistente no fato de que para esse a majorante pode ultrapassar o aumento de $1 / 3$, chegando até a metade.

A circunstância da chamada deficiência justificar-se-ia, a princípio - para qualquer caso de homicídio, reitere-se -, pela maior dificuldade de defesa por parte da vítima. Não se considera, entretanto, adequada a expressão utilizada, mesmo porque o comprometimento físico ou mental do sujeito passivo do delito pode vir a ser passageiro, razão pela qual melhor seria apontar a circunstância de ocorrência de qualquer dificuldade de autodefesa da vítima.

Quanto ao terceiro caso de aumento, para os feminicídios perpetrados na presença de descendente ou de ascendente da vítima, questiona-se, uma vez mais, a razão da previsibilidade desse aumento somente para casos de feminicídio. A circunstância nele descrita não caracteriza situação específica aos casos de feminicídio, podendo ser aplicado aos outros tipos de homicídio doloso. 
Assim, se configura mais uma incoerência da legislação penal e falha técnica do legislador, que entusiasmado com a expansão do sistema punitivo aplicou causas de aumento que não têm nenhuma relação com a discriminação contra a mulher. Neste diapasão, para que haja harmonia entre as normas penais, esses casos de aumento de pena só poderiam existir se aplicados a todas as formas de homicídio, ou não aplicados para nenhum dos casos. Referidas causas de aumento de pena revelam-se inadequadas na Lei ora discutida, vez que se o objetivo desta era dar maior visibilidade à morte de mulheres decorrentes de sua discriminação na sociedade, deveria ter-se restringido a isso, não se enveredando ao populismo penal.

\section{Estigmatização da mulher como vítima e vulnerável}

A lei em comento enseja ainda uma importante reflexão criminológica. $\mathrm{O}$ sistema penal e as mulheres tiveram uma paradoxal relação ${ }^{29}$ durante os séculos. Ele foi caracterizado por negar-lhes proteção, ignorando violações gravíssimas aos seus corpos e vidas e, o que é ainda pior, durante largo período, sendo o responsável pelo fomento de tais violações. ${ }^{30}$ Desde o início deste século, contudo, grupos vulneráveis que por muito tempo foram perseguidos pelo Direito Penal têm buscado sua proteção, o que enseja relevante debate.

A intervenção do Estado por meio do Direito Penal para a proteção das mulheres assume por vezes contornos paternalistas, alimentando a percepção da mulher como vítima e ser vulnerável. As características intrínsecas de tal ramo levam a uma dupla vitimização da mulher, que sofre, além do crime, os preconceitos e estereótipos que as instituições públicas reproduzem, como nos casos de estupro em que desde o momento da notícia-crime até a decisão, a vítima é constantemente questionada e seu comportamento e relato muitas vezes desqualificados.

A mulher foi historicamente caracterizada pelo Direito Penal como sujeito passivo dos crimes sexuais, considerada como um ser frágil, doméstico, dependente e com pouca capacidade de oferecer perigo à sociedade. O seu papel sempre foi o de vítima, enquanto a autoria dos crimes caberia ao homem, dominador e perigoso. ${ }^{31}$

\footnotetext{
29 AROCENA, Gustavo A.; CESANO, José Daniel. El delito de femicidio: aspectos político-criminales y análisis dogmático-jurídico. Montevideo: B de F, 2013. p. 13.

30 SOUZA, Luciano Anderson de. Crimes sexuais: reflexões críticas. In: SILVEIRA, Renato de Mello Jorge; RASSI, João Daniel (Org.). Estudos em homenagem a Vicente Greco Filho. São Paulo: LiberArs, 2014. p. 325-338.

31 MELlO, Marília Montenegro Pessoa de. Da mulher honesta à lei com nome de mulher: o lugar do feminismo na legislação penal brasileira. Videre, Dourados, v. 2, n. 3, p. 137-159, jan./jun. 2010. p. 138.
} 
Sob a influência do movimento feminista dos anos de 1960 e 1970, o sistema penal sofreu alterações, ainda que tardiamente no Brasil. Com a introdução da Lei Maria da Penha, em 2006, surgiram muitas críticas decorrentes da diferença de tratamento entre os gêneros envolvidos em crimes idênticos, mas com mudança de regrame se tivessem ocorrido dentro de um contexto de violência doméstica ou familiar contra a mulher. ${ }^{32}$ Com isso, alega-se, a norma penal continuou a posicionar a mulher como vítima, sujeito passivo que merece uma tutela especial.

Apesar desta crítica ainda estar presente na Lei do Feminicídio, ela tem especial destaque no caso da Lei Maria da Penha, ${ }^{33}$ que introduziu muitas mudanças no tratamento da violência doméstica familiar contra mulheres, punindo com maior recrudescimento os casos em que ocorre e acompanhada de uma menor liberdade da mulher dentro do Processo Penal. Deve-se atentar, à vista disso, às práticas que não dicotomizem ou acabem por fortalecer as separações entre mulher/vítima e homem/ agressor, ${ }^{34}$ que constituem reflexos do sistema penal patriarcal que reforça estereótipos ${ }^{35}$ de masculinidade e feminidade, sendo importantes políticas públicas que discutam relações de poder e promovam atuações que contemplem a complexidade e a diversidade dessa questão social.

\section{Populismo penal e Direito Penal simbólico}

Por fim, pode-se deparar com a crítica quanto à utilização do próprio Direito Penal no enfrentamento da violência de gênero. Muitos autores argumentam que o sistema penal não cumpre com a garantia de direitos, sendo ele próprio grande violador dessa, não atendendo sua função preventiva, porque a pena é incapaz de prevenir ou ressocializar, somente reproduzindo a criminalidade e as relações sociais de dominação. Como única solução, o sistema penal jamais seria eficaz, entretanto, ele tem sido visto como estratégia de enfrentamento mais ou menos operativo, atuando, em conjunto com outras políticas, na desconstrução de paradigmas. ${ }^{36}$

32 MELLO, Marília Montenegro Pessoa de. Da mulher... cit., p. 139.

33 As críticas à Lei n. 11.340/2006 nesse sentido são encontradas em maior detalhe em MELLO, Marília Montenegro Pessoa de. Da mulher... cit., p. 137-159.

34 BEIRAS, Adriano; MORAES, Maristela; ALENCAR-RODRIGUES, Roberta de; CANTERA, Leonor M. Políticas e leis sobre violência de gênero reflexões críticas. Psicologia \& Sociedade, Porto Alegre, v. 24, n. 1, p. 36-45, jan./abr. 2012. p. 42.

35 Sobre construção de estereótipos no Processo Penal, cf.: MACHADO, Marta Rodriguez de Assis (Coord.) et al. A violência doméstica fatal: o problema do feminicídio íntimo no Brasil. Brasília: Ministério da Justiça, Secretaria de Reforma do Judiciário, 2015. passim.

36 MACHADO, Isadora Vier; ELIAS, Maria Lígia G. Granado. A Lei Maria da Penha completa nove anos: é possível trilhar caminhos para além de sua dimensão simbólica? Boletim IBCCRIM, São Paulo, n. 281, p. 14-15, abr. 2016. p. 14-15. 
As críticas à tipificação se voltam, portanto, à adesão de movimentos feministas ao sistema penal, sendo visto como um paradoxal entusiasmo pela punição. ${ }^{37}$ Há algum tempo, ativistas e movimentos feministas e de direitos humanos têm feito parte da pressão pela expansão do poder punitivo, globalmente. ${ }^{38}$ Visando punir seus "inimigos", têm contribuído para o maior rigor penal que acompanha a supressão de direitos humanos fundamentais, contraditoriamente intensificando a violência assim como os danos e as dores inerentes ao sistema punitivo.

O sistema penal é, obviamente, incapaz de uma atuação positiva quanto a ações afirmativas. Seu sentido se encontra na proibição de condutas, intervindo concretamente após o fato acontecido, com a imposição da pena e restrição de direitos que lhe são subjacentes. ${ }^{39}$ Ademais, o que dispositivos garantidores de proteção de direitos humanos - inscritos nas declarações universais e constituições democráticas - ordenam aos Estados são intervenções positivas que criem condições econômicas, sociais e políticas para a efetiva realização dessas garantias, de forma a promover, e não negar, direitos. Nesse sentido, argumenta-se que as leis penais criminalizadoras nada tutelam e não evitam a ocorrência das condutas que criminalizam, mas, ao contrário, exercem o poder punitivo de forma a promover a violência, estigmatização e sofrimento. ${ }^{40}$

Apesar das críticas, todavia, o tratamento penal mais recrudescido à situação em análise se justifica pela prática configurar enorme gravidade, ${ }^{41}$ referente a um importante bem jurídico. O objetivo da lei penal na hipótese não possui cunho emancipador, já que este certamente não é seu papel, mas sim desvelar a maior censurabilidade da conduta frente a um incisivo ataque a um interesse humano fundamental, já vulnerável na realidade concreta. ${ }^{42}$

37 KARAM, Maria Lúcia. Sistema penal e direitos da mulher. Revista Brasileira de Ciências Criminais, São Paulo, v. 3, n. 9, p. 147-163, jan./mar. 1995. p. 147-163.

38 Quanto a este fenômeno, no geral, por todos, cf. SILVA SÁNCHEZ, Jesús-María. La expansión del derecho penal. Aspectos de la política criminal en las sociedades postindustriales. 2. reimp. de la 2. ed. amp. Montevideo: B de F, 2008. p. 64-68.

39 Aliás, com propriedade, Roxin assevera que o Direito Penal se caracteriza por suas sanções. Cf. ROXIN, Claus. Derecho penal: parte general. Fundamentos. La estructura de la teoria del delito. Traducción de La 2. Edición alemana y notas por Diego-Manuel Luzón Peña, Miguel Díaz y García Conlledo e Javier de Vicente Remesal. Madrid: Civitas, 2008. t. 1. p. 41.

40 ANDRADE, Vera Regina Pereira de. A soberania patriarcal: o sistema de justiça criminal no tratamento da violência sexual contra a mulher. Revista Brasileira de Ciências Criminais, São Paulo, v. 12, n. 48, p. 260290, mai.jun. 2004. p. 260-290.

${ }^{41}$ GOMES, Izabel Solyszko. Feminicídios e possíveis respostas penais: dialogando com o feminismo e o direito penal. Revista Gênero \& Direito, João Pessoa, v. 4, n. 1, p. 188-218, 2015. Disponível em: <http:// periodicos.ufpb.br/ojs2/index.php/ged/article/view/24472/13619>. p. 188-218.

42 Bárbara Rondero observa: "No usar el Derecho Penal para estos delitos resultaría absurdo. No nos equivoquemos, estamos hablando de violencia contra las mujeres. No se murieron. Las mataron. Cuando se establecen las agravantes del homicidio o el homicidio calificado, es para sancionar no que hayan matado, sino cómo las mataron. Es la lógica del mundo penal para poder establecer las calificaciones. Desde este 
Ademais, a visibilização do gênero dentro dos homicídios contra as mulheres pode ter sua importância ${ }^{43}$ como uma das ferramentas aplicadas para alterar padrões de desigualdade, oferecendo uma atuação simbólica do direito sobre as relações de gênero. A criminalização consagra o papel simbólico de demonstrar que tal conduta é reprovável, sinalizando publicamente a importância da questão. Seu efeito simbólico é um elemento importante de formação da identidade e escolhas dos sujeitos, tendo impactos diretos na liberdade e na relação entre os sujeitos. A simbologia é ínsita direito penal, não se confundindo com mero simbolismo.

Pela lógica do Direito Penal, o conflito é individualizado, vez que o sistema penal trabalha com os casos de violência como se fossem casos isolados, sendo raramente apresentadas visões que explicitem a violência doméstica como estruturante das relações sociais. É também visando isso que a Lei do Feminicídio demonstra sua importância, pois coloca o assassinato da mulher dentro de um contexto de discriminação de gênero que deve ser considerado pelo aplicador da lei.

Com a tipificação do feminicídio é possível, então, contribuir para superar o conceito reducionista de violência de gênero somente no contexto doméstico. ${ }^{44}$ Ademais, é verificada a função política do conceito, para combater a resistência ainda presente na sociedade e nos meios jurídicos que negam a raiz discriminatória das agressões, reduzidas a atos isolados feitos por sujeitos desequilibrados. Com a publicização da violência de gênero e a nomeação dos casos em que a dominação das mulheres pela sociedade machista chega ao ápice do assassinato, o recrudescimento do tratamento penal demonstra que comportamentos misóginos não serão aceitos.

Reconhece-se, no entanto, as limitações do sistema penal, que apesar de atender ao anseio social, leva a uma supressão de direitos, muitas vezes não sendo positivos seus resultados. Depreende-se daí, além da perene busca por seu aperfeiçoamento, a necessidade de combiná-lo com outras estratégias de ação e políticas públicas.

\section{Conclusão}

A violência contra a mulher não é algo recente. Ao revés, possui longínqua origem histórica, cultural e estrutural, tendo sido por muito tempo o gênero feminino visto como inferior e subordinado ao homem e às instituições por ele comandadas. Não se

punto de vista, se hace necesario un tipo penal que califique cómo están matando a estas mujeres, y en qué condiciones - que no son las mismas que contiene el homicidio calificado". Apud CHIAROTTI, Susana (Ed.). Contribuciones al debate sobre la tipificación penal del feminicidio/femicidio. Lima: CLADEM, agosto 2011. p. 203.

43 MACHADO, Marta Rodriguez de Assis (Coord.). A violência... cit., p. 65.

44 COPELlO, Patricia Laurenzo. ¿Hace falta... cit., p. 255-256. 
supõe, evidentemente, a aprovação da lei em comento como pronta solução para a questão da violência de gênero. No entanto, constitui a criação do feminicídio como destacada censura a situação de vulnerabilidade, a qual, em conjunto com outras medidas, poderá possibilitar a construção de novas formas de poder e de diminuição da dominação das mulheres.

O âmbito jurídico não pode ser considerado um fim em si mesmo, e muito menos uma solução imediata e automática aos objetivos sociais visados, devendose manter seu monitoramento, como condição para sua efetividade. ${ }^{45}$ Dessa forma, é imprescindível a continuidade da supervisão das decisões judiciais aos casos em que pode ser aplicada a qualificadora do feminicídio, assim como dos dados estatísticos de mortes de mulheres e das situações em que elas são mortas.

Para que ocorra a prevenção de todas as formas de violência contra mulheres, sinaliza-se ser necessária uma abordagem sistemática que inclua não só medidas legislativas, mas também e, precipuamente, políticas, de proteção a sobreviventes e demais vulneráveis, coleta de dados e pesquisa, com intervenções abrangentes, coordenadas e integradas que abordem as causas profundas da violência, incluindo causas sócio-econômicas, como a pobreza, a discriminação de gênero e a desigualdade, com a integração de serviços de saúde a um amplo serviço social, com políticas afirmativas, como cotas para mulheres em cargos eletivos, cargos públicos e empresas, reduções tributárias diferenciadas, tudo aliado a programas educativos e de acolhimento. Somente assim poderá haver a efetivação do princípio da igualdade em nossa dificultosa realidade.

São Paulo, 29 de abril de 2016.

\section{Referências}

ANDRADE, Vera Regina Pereira de. A soberania patriarcal: o sistema de justiça criminal no tratamento da violência sexual contra a mulher. Revista Brasileira de Ciências Criminais, São Paulo, v. 12, n. 48, p. 260-290, mai./jun. 2004.

AROCENA, Gustavo A.; CESANO, José Daniel. El delito de femicidio: aspectos político-criminales y análisis dogmático-jurídico. Montevideo: B de F, 2013.

BEIRAS, Adriano; MORAES, Maristela; ALENCAR-RODRIGUES, Roberta de; CANTERA, Leonor M. Políticas e leis sobre violência de gênero reflexões críticas. Psicologia \& Sociedade, Porto Alegre, v. 24, n. 1, p. 36-45, jan./abr. 2012.

45 RIFIOTIS, Theophilos. Judiciarização das relações sociais e estratégias de reconhecimento: repensando a 'violência conjugal' e a 'violência intrafamilia'. Revista Katálysis, Florianópolis, v. 11, n. 2, p. 225-236, jan. 2008. p. 230. 
BITENCOURT, Cezar Roberto. Tratado de direito penal. São Paulo: Saraiva, 2014, v. 1.

. Tratado de direito penal. São Paulo: Saraiva, 2016, v. 2.

BOURDIEU, Pierre. A dominação masculina. Rio de Janeiro: Bertrand Brasil, 2010.

CASTILHO, Ela Wiecko Volkmer de. Sobre o feminicídio. Boletim IBCCRIM, São Paulo, v. 270, p. 4-5, maio 2015 .

CHIAROTTI, Susana (Ed.). Contribuciones al debate sobre la tipificación penal del feminicidio/ femicidio. Lima: CLADEM, agosto 2011.

CHUECA SANCHO, Ángel. Vulnerabilidad de las mujeres, principio de igualdad y no discriminación y derechos humanos. In: ALCOCEBA GALLEGO, Amparo; QUISPE REMÓN, Florabel (Coord.). Feminicidio: el fin de la impunidad. Valencia: Tirant lo Blanch, 2013. p. 37-53.

COPELLO, Patricia Laurenzo. ¿Hace falta un delito de feminicidio? Revista de Derecho Penal, Montevidéu, v. 20, p. 243-256, 2012.

COUTO, Edvaldo Souza. Transexualidade. O corpo em mutação. Salvador: Grupo Gay da Bahia, 1999.

GOMES, Izabel Solyszko. Feminicídios e possíveis respostas penais: dialogando com o feminismo e o direito penal. Revista Gênero \& Direito, João Pessoa, v. 4, n. 1, p. 188-218, 2015. Disponível em: <http://periodicos.ufpb.br/ojs2/index.php/ged/article/view/24472/13619>.

KARAM, Maria Lúcia. Sistema penal e direitos da mulher. Revista Brasileira de Ciências Criminais, São Paulo, v. 3, n. 9, p. 147-163, jan./mar. 1995.

LAPALUS, Marylène. Feminicidio/femicidio: les enjeux théoriques et politiques d'un discours définitoire de la violence contre les femmes. Enfances, Familles, Générations, [S.1.], n. 22, 2015, p. 85-113. Disponível em: <http://www.efg.inrs.ca/index.php/EFG/article/view/432/255>.

MACHADO, Isadora Vier; ELIAS, Maria Lígia G. Granado. A Lei Maria da Penha completa nove anos: é possível trilhar caminhos para além de sua dimensão simbólica? Boletim IBCCRIM, São Paulo, n. 281, p. 14-15, abr. 2016.

MACHADO, Marta Rodriguez de Assis (Coord.) et al. A violência doméstica fatal: o problema do feminicídio íntimo no Brasil. Brasília: Ministério da Justiça, Secretaria de Reforma do Judiciário, 2015.

MELLO, Marília Montenegro Pessoa de. Da mulher honesta à lei com nome de mulher: o lugar do feminismo na legislação penal brasileira. Videre, Dourados, v. 2, n. 3, p. 137-159, jan./jun. 2010.

RADFORD, Jill; RUSSELL, Diana E. H. Femicide: the politics of woman killing. New York: Twayne Publishers, Sept. 1992. 
RIFIOTIS, Theophilos. Judiciarização das relações sociais e estratégias de reconhecimento: repensando a 'violência conjugal' e a 'violência intrafamilia'. Revista Katálysis, Florianópolis, v. 11, n. 2, p. 225-236, jan. 2008.

ROXIN, Claus. Derecho penal: parte general. Fundamentos. La estructura de la teoria del delito. Traducción de La 2. Edición alemana y notas por Diego-Manuel Luzón Peña, Miguel Díaz y García Conlledo e Javier de Vicente Remesal. Madrid: Civitas, 2008. t. 1.

SILVA SÁNCHEZ, Jesús-María. La expansión del derecho penal. Aspectos de la política criminal en las sociedades postindustriales. 2. reimp. de la 2. ed. amp. Montevideo: B de F, 2008.

SOUZA, Luciano Anderson de. Crimes sexuais: reflexões críticas. In: SILVEIRA, Renato de Mello Jorge; RASSI, João Daniel (Org.). Estudos em homenagem a Vicente Greco Filho. São Paulo: LiberArs, 2014. p. 325-338.

SOUZA, Luciano Anderson de; FERREIRA, Regina Cirino Alves, Feminicídio: primeiras observações. Boletim IBCCRIM, São Paulo, n. 269, p. 3-4, abril 2015.

SOUZA, Regina Cirino Alves Ferreira de. Ódio e direito penal. Dissertação (Mestrado) - Faculdade de Direito, Universidade de São Paulo, São Paulo, 2016.

TOLEDO VÁSQUEZ, Patsilí. Femicidio/feminicidio. Buenos Aires: Didot, 2014.

WAISELFISZ, Julio Jacobo. Mapa da violência 2015. Homicídio de mulheres no Brasil. Brasília: FLACSO, 2015. Disponível em: <http://www.mapadaviolencia.org.br/pdf2015/ MapaViolencia_2015_mulheres.pdf>.

ZANELLA, Everton; FRIGGI, Márcio; ESCUDEIRO, Marcio; AMARAL, Virgílio. Feminicídio: considerações iniciais. Centro de Apoio Operacional Criminal do Ministério Público do Estado de São Paulo. São Paulo, 2 de junho de 2015. Disponível em: <http://www.mpsp.mp.br/portal/page/ portal/cao_criminal/Artigos>. 
